\title{
Turing's Sunflowers: Public research and the role of museums
}

\author{
Ann Borda \\ Centre for the Digital Transformation of Health \\ University of Melbourne \\ Australia \\ aborda@unimelb.edu.au
}

\author{
Jonathan P. Bowen \\ School of Engineering \\ London South Bank University \\ United Kingdom \\ jonathan.bowen@lsbu.ac.uk
}

\begin{abstract}
In recent years, public engagement in museums is increasingly being influenced by the paradigm of "citizen science", that is, active participation in research teams by members of the general public with no formal training in the field of research concerned. This paper provides an overview of citizen science approaches which museums can deploy using online platforms, digital tools and apps. It also aims to highlight challenges and innovations, as well as possible opportunities for cultural organisations to include public participation in research and knowledge creation.
\end{abstract}

Alan Turing. Citizen science. Crowdsourcing. Museums. Public engagement. Public research.

\section{BACKGROUND}

Public collaboration in major projects through crowdsourcing is not a new phenomenon (Proctor 2013). An early and successful example was the public's help in finding quotations involving words included in the Oxford English Dictionary, started in the late $19^{\text {th }}$ century under the editorship of the lexicographer James Murray (1837-1915, see Figure 1), working in his "scriptorium", especially built in his North Oxford garden (Winchester 2003).

Of course, the technology of the Internet was not available for communication, but the postal service was very efficient with several collections and deliveries each day. Such was the demand for outgoing letters that a post box was installed immediately outside James Murray's house (see Figure 2). This acted is the equivalent of a personal Internet router, if somewhat slower in operation.

With the advent of the Internet, and more specifically the World Web Wide, the opportunity for fast international communication was greatly enhanced, and museums began to take advantage of the possibility of increasing their reach. Initially communication was largely one-way, with museums providing websites and "virtual museum" experiences (Gaia et al. 2020). As museums gained more experience, they developed more interaction with their online communities (Beler et al. 2004; Giannini \& Bowen 2019, Part V Audiences).

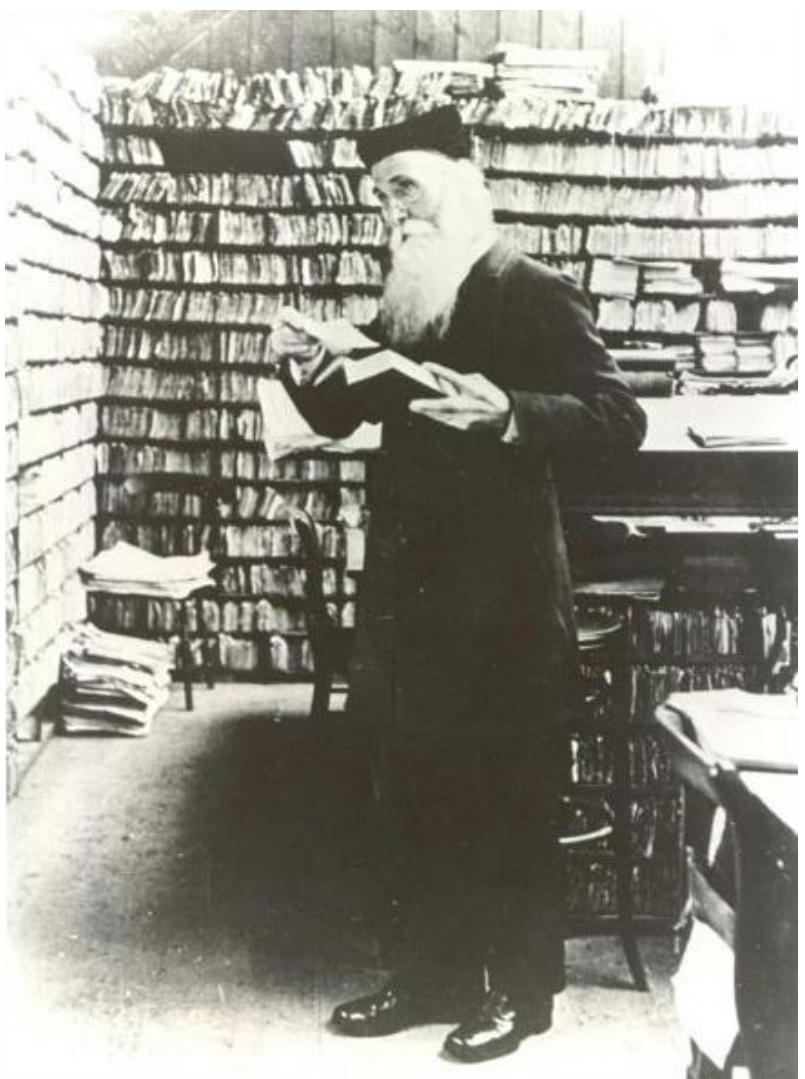

Figure 1: The lexicographer James Murray in his "scriptorium", surrounded by notes from his Oxford English Dictionary crowdsourcing project. (Wikimedia Commons,

https://commons.wikimedia.org/wiki/File:James-Murray.jpg) 


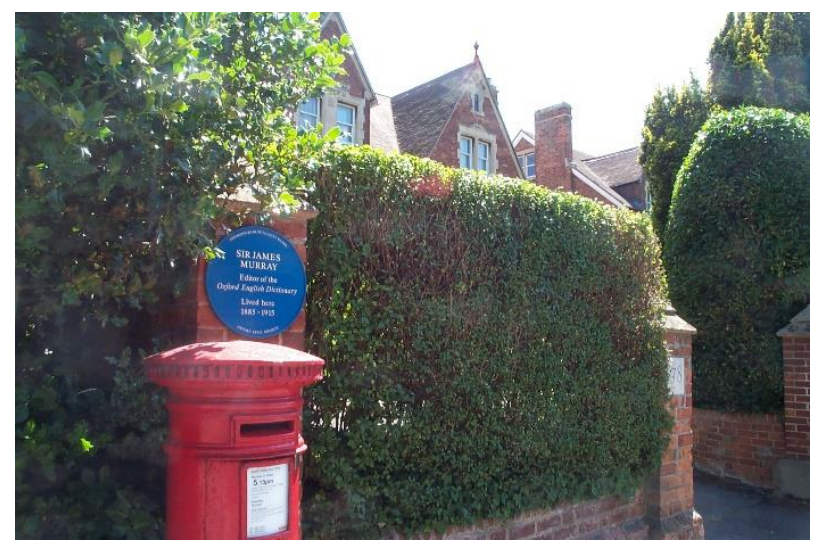

Figure 2: The post box outside James Murray's house in North Oxford, used to improve the speed of

communication for his early crowdsourcing project, now celebrated with a blue plaque.

(Wikimedia Commons, https://commons.wikimedia.org/wiki/File:78 Banbury Road Oxford 20060715.jpg)

Virtual collaboration has increased online in general as well as for museums (Borda and Bowen 2011). It is possible to visualise these collaborative communities in ways that help in understanding their structure (Bowen 2013). Various technologies are available to aid in online community development. Wikipedia is one very successful example of this. Some museums have employed wiki technology, as used by Wikipedia, to enable online collaborative projects of their own with their public (Bowen 2008; Liu and Bowen 2011).

Scientific institutions such as the Royal Society have significantly improved their web presence over the years (Bowen and Borda 2009). Scientists have also realised the potential of the web to using the public in aid their research in what has become to be known as "citizen science" (Wikipedia 2020; Borda, Gray and Downie 2019) - that is, active participation in research teams by members of the general public with no formal training in the field of research concerned (Irwin 1995).

This paper provides an overview of citizen science approaches, which museums can deploy using online platforms, digital tools, and apps. It also aims to highlight challenges and innovations (Borda and Bowen 2019), as well as possible opportunities for cultural organisations to include public participation in research and knowledge creation.

\section{TURING'S SUNFLOWERS}

In 2012, the Museum of Science and Industry (MOSI, now known as the Science and Industry Museum) in Manchester, the Manchester Science Festival, and The University of Manchester paid tribute to computer scientist (Bowen 2017), mathematician and philosopher, Alan Turing (19121954) (Hodges 1983/2012; Bowen 2012, Copeland et al. 2017) in a large public experiment to grow
3,000 sunflowers. Before his death, Alan Turing became fascinated by how mathematics work in nature - also known as morphogenesis (Turing 1952; Bowen 2016). Specifically, Turing noticed that the Fibonacci sequence, often occurred in sunflower seed heads (see Figure 3 ), and he started to grow sunflowers in order to observe them and their Fibonacci sequences. The first two numbers in the Fibonacci sequence are, by definition, 0 and 1, and each subsequent number is the sum of the previous two numbers $(2,3,5,8,13,21,34,55$, etc.).



Figure 3: Helianthus flower spiral pattern based on Fibonacci numbers 34 and 55.

(Wikimedia Commons,

https://commons.wikimedia.org/wiki/File:Helianthus whorl.jpg)

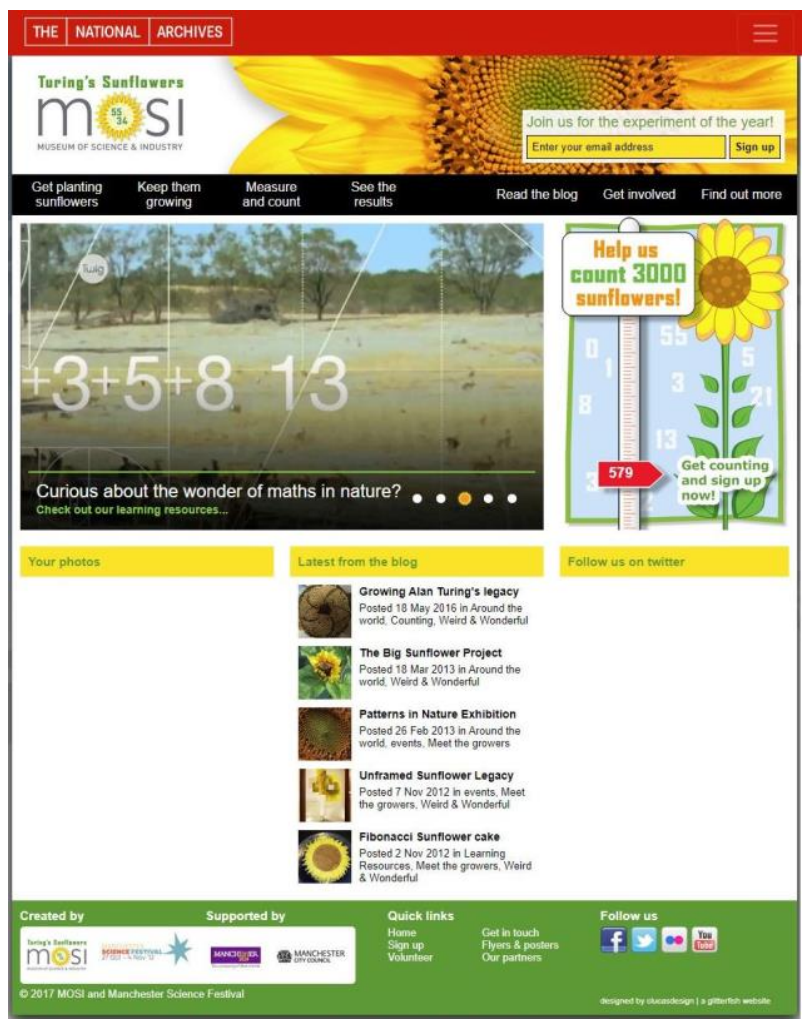

Figure 4: MOSI Turing's Sunflowers website, archived by the National Archives, UK (http://www.turingsunflowers.com). 
On the centenary anniversary of Turing's birth, this citizen science study initiated by MOSI, invited the public to evaluate the occurrence of Fibonacci structures in the spirals of sunflowers (Helianthus annuus) and to upload their findings to a dedicated website (see Figure 4). The public contributions led to an important research paper in the Royal Society Open Science journal - the same scientific society that published Turing's own observations on morphogenesis, the development of shape in biological organisms (Swinton and Ochu 2016; Turing 1952).

\section{PUBLIC ENGAGEMENT IN MUSEUMS}

\section{The Role of Citizen Science}

Turing's Sunflowers is a prime example of public engagement in museums which is increasingly being influenced by the paradigm of citizen science.

Citizen science as an approach for public engagement in research dates back well over a century in some fields of research, for example, natural history, where the US Audubon Society's Christmas Bird Count began in 1900 (Irwin 1995; Bonney 2009). Citizen science activity has dramatically increased in the $21^{\text {st }}$ century, influenced by societal and technological changes and participatory democracy. Digital technologies have exponentially enhanced both citizen scientists' experiences and researchers' ability to access and process collected data. This has enabled the largescale collection and processing of scientific data and widespread dissemination of scientific knowledge and discoveries, e.g., in environmental sciences, astronomy, medicine, and social sciences (Irwin 1995; Bonney 2009; Shirk et al. 2012).

With the momentum and practice of citizen science over several decades, citizen science has only been recently formalised through communities of practice organisations. In 2014, the Citizen Science Association (CSA) based at the Cornell Laboratory of Ornithology in the US and the European Citizen Science Association (ECSA) were established. Museums have a role in the various associations; e.g., the Australian Citizen Science Association (ACSA) formed in 2015 was hosted by the Australian Museum in Canberra (Borda, Gray and Downie 2019). The ECSA is administered by the Museum für Naturkunde Berlin and has had notable support from natural history museums in Europe in its establishment (Sforzi et al. 2018). Natural history museums have a long history of collaboration with the amateur-expert naturalist community in a wide range of field-based and online citizen science projects on biodiversity and conservation (Ballard et al. 2017; Sforzi et al. 2018).
In 2015, ECSA published Ten Principles of Citizen Science (ECSA 2015), which was developed by ECSA's working group on sharing best practice and building capacity led by the Natural History Museum in London, with input from ECSA members. These working principles have been adopted by the associations and other citizen science organisations highlighting the common good aspects of the involvement of public members in research which, can generate new knowledge or understanding, provide benefits to science and society, support reciprocity, ethical approaches and publicly available results.

\section{Participation}

In the literature, citizen science projects have been differentiated according to the extent of responsibilities that the public undertake as research activities, such as collecting and analysing data (contributory) and interpreting and disseminating results (collaborative). Projects are typically instigated by professionally trained researchers in which citizen scientists are supporting tasks in a research process (Bonney 2009; Shirk et al. 2012); however, community scaled participatory research projects, for example, can be a cooperative activity (Boiano et al. 2019). This may lead to co-creation in which researchers and members of the public work together, for example, in defining a research problem or producing new knowledge (Borda, Gray and Fu 2019). Citizen-led or extreme citizen science approaches aim to provide tools and methods to enable communities to develop their own projects to address issues that directly concern them (Haklay 2018).

\section{Platforms and tools}

A number of platforms have been established within the last twenty years supporting online citizen science projects.

The Zooniverse (http://www.zooniverse.org) is one of the largest and oldest research platforms for the volunteer public and researchers to collaborate on scientific studies. It is a partnership of professional scientists based in Oxford University (UK), the Adler Planetarium in Chicago (US), the University of Minnesota, and individual project research teams. The first project launched in 2007 was the highly successful Galaxy Zoo designed to record the shapes of different galaxies. In 2014, Zooniverse reached one million volunteers, and currently hosts over 200 projects from across the sciences and humanities, including museum research partnerships among these.

Scistarter (http://scistarter.com) is another multidiscipline citizen science platform which lists over 2,700 citizen science projects. Established in 2014, 
Scistarter has collaborations with the US National Science Foundation, Arizona State University's Center for Engagement and Training in Science and Society, NASA, Girl Scouts of America, among other educational and research organisations.

More institutionally focused platforms are also supporting projects, such as the National Geographic Citizen Science Projects website (http://www.nationalgeographic.org/idea/citizenscience-projects/) and Cornell Lab of Ornithology (http://www.birds.cornell.edu) home to the eBird global observatory (https://ebird.org) with more than 100 million bird sightings contributed per year.

In addition to hosting, some platforms provide tools for citizen science project support and development: for example, the Zooniverse Project Builder (http://www.zooniverse.org/lab) and the Citsci.org Project Builder (http://www.citsci.org). Citsci is an initiative developed through the Natural Resources Ecology Lab at Colorado State University and supported by the US-based Citizen Science Association (http://citizenscience.org). Additionally, there are several web-based platforms that support public contribution of data and task-based activities to scientific projects, such as the World Community Grid (https://www.worldcommunitygrid.org) and EpiCollect+ (https://five.epicollect.net).

Mobile app versions of citizen science platforms and projects - e.g., Zooniverse and iNaturalist - are increasing in their availability and reach. Mobile and smartphone devices are becoming pervasive tools of digitally-enabled citizen science. These devices and supporting apps can automate data collection and incorporate key data gathering functions, such as capturing images, audio and text into a single tool that can "stamp" the date, time and geographic coordinates (Haklay 2018). The Smithsonian Institution, for instance, has partnered with researchers to develop a free app called Leaf Snap (http://leafsnap.com) which can help identify tree species from photographs of their leaves.

\section{CROWDSOURCING}

Engaging a distributed public using digital platforms and tools is often undertaken through crowdsourcing - a form of digitally enabled citizen science. Crowdsourcing also allows for the collection and analysis of data on a much larger scale meaning efficiency gains can be made in terms of speed, throughput and cost.

Crowdsourcing has been a particularly visible form of participation within the cultural sector (Ridge 2014; Corbeil et al. 2017; Bonacchi et al. 2019). The term crowdsourcing was coined by Jeff Howe in 2006 in the context of a business driver (Howe
2008). In the context of this chapter, Ridge (2014) defines cultural heritage crowdsourcing projects as "projects [that] ask the public to undertake tasks that cannot be done automatically, in an environment where the activities, goals (or both) provide inherent rewards for participation, and where their participation contributes to a shared, significant goal or research interest."

Crowdsourcing in cultural heritage can take different forms (Owens 2013; Ridge 2014) but largely rely on the use of digital tools and platforms and some aspect of data collection, analysis or processing. A breakdown of common data tasks is described in the following subsections (Hedges and Dunn 2017).

\section{Correcting Text}

Large-scale digitisation projects of textual archives and collections often use Optical Character Recognition (OCR) which can be error-prone and require manual correction. An example of a crowdsourced correction project is the online Australian Historic Newspapers website (http://trove.nla.gov.au/newspaper/). The National Library of Australia invited the Australian public to identify and proofread newspapers (from the years 1803 to 1954) scanned with OCR technology. The project was launched in 2008, and two years later more than 12 million lines of text had been corrected.

\section{Creating Content}

Crowdsourcing new content can be a means to gather resources that are "owned" by the public to enrich collections, or building new ones (e.g., personal narratives, personal memorabilia, and information). An example is the 1001 Stories of Denmark curated by the Danish Agency for Culture (http://www.kulturarv.dk/1001fortaellinger/en GB), which displays stories about places, cultural heritage and history. The website is user-driven, and participants can contribute photos, stories and recommendations for personal sightseeing routes.

\section{Georeferencing}

Georeferencing is the process of establishing the location of unreferenced geographical information in terms of a modern coordinate system, such as latitude and longitude. An example is the online Georeferencer project organised by the British Library (http://www.bl.uk/projects/georeferencer), which aims to "geo-enable" over 50,000 historical maps in its collections by asking participants to place historic maps over contemporary ones and assign spatial coordinates to these digitised map images, making it then possible to search, and compare the past with the present. Volunteered Geographic Information (VGl) is among the most abundant type 
of crowdsourced data (Hedges and Dunn 2017; Haklay 2018).

\section{Social Tagging}

Social tagging or folksonomies may be regarded as crowdsourcing organisational information. Tags can be based on controlled vocabularies but are often derived from free text supplied by the participants e.g., image tagging in Flickr (Hedges and Dunn 2017).

The steve.museum project was a collaborative effort to improve public access to and engagement with US-based art collections. It explored the possibilities of user-generated descriptions of works of art. Art museums, including the Guggenheim Museum, the Cleveland Museum of Art, the Metropolitan Museum of Art and the San Francisco Museum of Modern Art, as well as Archives \& Museum Informatics, were involved in the initiative (Wyman et al. 2006).

\section{Transcribing}

Transcribing is used to address a major challenge with digitisation, namely the difficulty of rendering handwriting into machine-readable form.

Old Weather (http://www.oldweather.org) is one of the earlier transcription projects hosted on Zooniverse. It is a collaboration of archival and scientific institutions, museums and universities in the UK and USA. The project involves the transcription of ships' logbooks held by the UK National Archives, in order to better access the weather observations. These logs contain information that can potentially contribute to climate research and climate model predictions.

The Tate in the UK was the first art gallery to collaborate with the Zooniverse team to crowdsource text transcriptions of handwritten documents from artist's archives, such as Barbara Hepworth, Walter Sickert, and Francis Bacon. Begun in 2015, participants in the AnnoTate project (http://anno.tate.org.uk) can browse the collections and type up Francis Bacon's letters to his art dealer or the notes in the British artist Donald Rodney's sketchbooks, and in the process could encounter new discoveries contained in these works.

\section{Data Analysis and Problem-solving}

Crowdsourced data processing can further involve both lay-people and those knowledgeable in a discipline (Hedges and Dunn 2017), particularly where complex tasks e.g., forms of annotation or relational tasks or problem-solving are applied, e.g., image processing of archaeological data, as in the MicroPasts project (see Figure 5).
MicroPasts was established in 2013 by a research team at the University College London (UCL) Institute of Archaeology and the British Museum, with recent coordination provided by researchers at the University of Cambridge's Fitzwilliam Museum and the University of Stirling (Bonacchi et al. 2019). The aim is to leverage crowd- and web-based methods to create collaborations between the public and researchers, in order to co-produce data and knowledge about the human past.

Rekrei (https://projectmosul.org) is an international crowdsourcing project on lost cultural heritage, arising from the destruction of the city of Mosul in Iraq. The project aims to collect photographs of monuments, museums, and artefacts damaged by natural disasters or human intervention, "and to use those data to create 3D representations and help to preserve our global, shared, human heritage." The online platform supports the organising and management of digital photos and other media volunteered by the public and subsequently the photogrammetric reconstructions of artefacts and heritage sites are also performed by volunteers (Vincent et al. 2015).

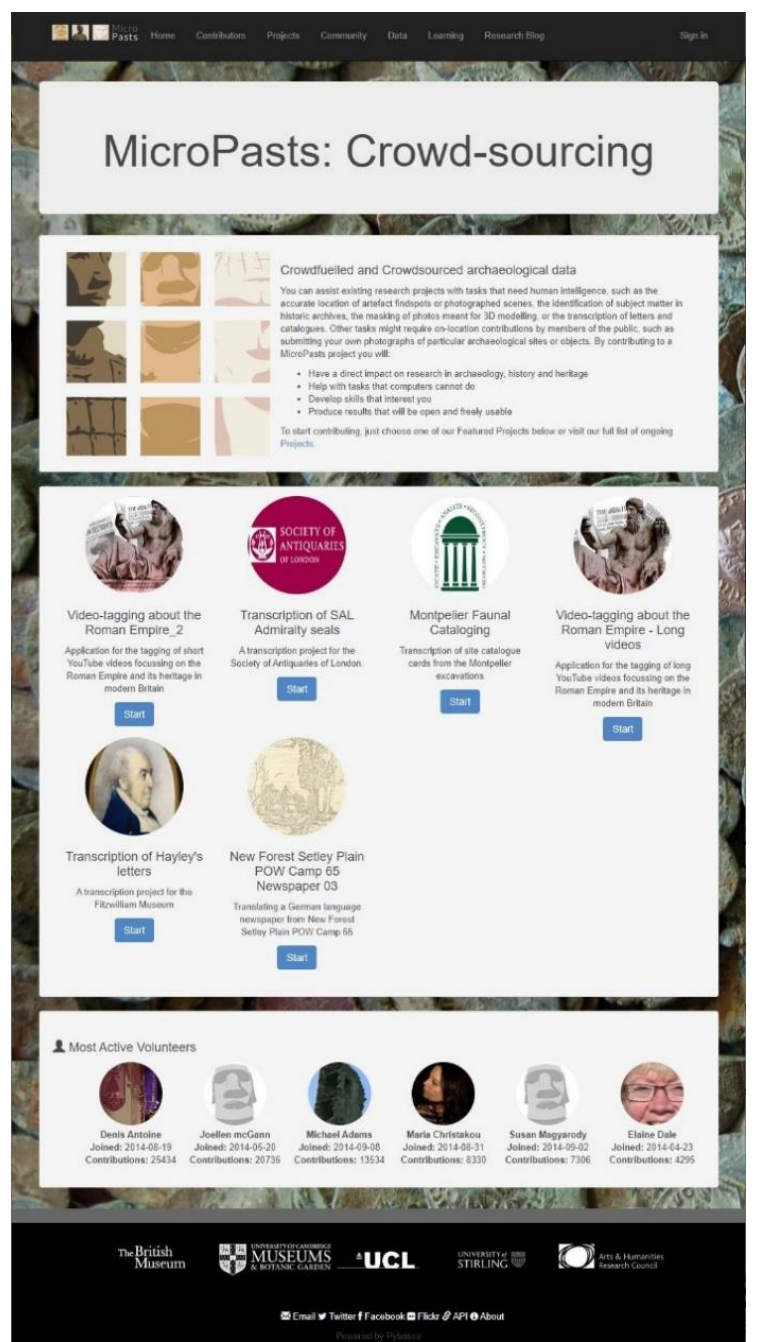

Figure 5: MicroPasts crowdsourcing projects (http://crowdsourced.micropasts.org). 
The use of gamification or "serious games" - is a digitally-enabled method to support participatory research. Serious games are usually developed by professional scientists, such as the DNA sequence alignment online game Phylo (see Figure 6) and EyeWire (http://eyewire.org). Eyewire is hosted at the Massachusetts Institute of Technology inviting the public to map neurons in the retina. Serious games are further instances of contribution by the public in problem-solving tasks being adopted by museums in both research and educational contexts (Curtis 2014; Wang and Nunes 2019).

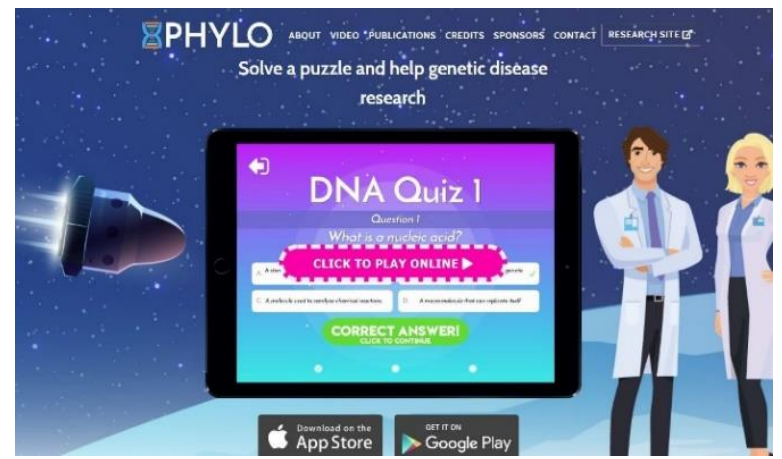

Figure 6: Phylo puzzle website (McGill University, http://phylo.cs.mcgill.ca).

\section{Machine Learning}

Returning to Alan Turing's Sunflowers, it is perhaps appropriate to raise awareness of the potential of machine learning and artificial intelligence ( $\mathrm{Al}$ ) in empowering crowds and enhancing their value. There is a recognised value in algorithmic diversity alongside human intelligence. This opportunity seems to be particularly associated with online citizen science and crowdsourced platforms which use algorithms alongside human intelligence - as in serious games, e.g., Foldit (Curtis 2014) - where large volumes of data lend themselves to be used as "training datasets" for machine learning algorithms (Ceccaroni 2019; Leach et al. 2020).

Crowdsourcing often makes use of the power of human computation to solve tasks that remain difficult to solve with computers alone, such as determining whether a digital image contains a certain type of object. The iNaturalist platform (https://www.inaturalist.org), supported by the National Geographic Society, enables citizen scientists and ecologists from around the world to upload observations from the natural world, such as images of animals and plants. It has an image recognition platform that includes an automated species/taxonomic-identification machine-learning algorithm applied to computer vision. Images can be identified via an Al model that has been trained on "research grade" observations on iNaturalist (Ceccaroni et al. 2019).
A novel advancement in the use of social tagging, the San Francisco Museum of Modern Art (SFMOMA) has developed Send Me SFMOMA (http://www.sfmoma.org/send-me-sfmoma/), an SMS "chatbot" service providing an accessible method of sharing the breadth of SFMOMA's collection with the public, of which only $5 \%$ is seen in the Galleries at any one time (Mollica 2017; Gaia et al. 2019). Using the service and texting the words "send me" followed by a keyword, a colour, or an emoji, a visitor receives a related artwork image and caption via text message. Such crowdsourced tags (or "labels") can be used as new ways of identifying and describing objects, e.g., found in images, or geo-location data in maps, which are then helping to develop Al-enabled apps, e.g., Leaf Snap, to match tags to objects more precisely (Leach et al. 2020).

\section{Data quality assurance}

In an often highly data intensive environment, ensuring data quality, accuracy, consistency and completeness can be an issue in citizen science projects, and a limitation for those considering the involvement of public in research (Kelling et al. 2015; Borda, Gray and Fu 2019). Some suggest that a lay public untrained in scientific data management or research integrity may be more prone to systematic errors, which can impact data quality in processing and analysis tasks, for instance. In this regard, museums can be equipped to provide training or close supervision where feasible in a fieldwork context; e.g., the Natural History Museum in London offers orientation and training for both the public and researchers (http://www.nhm.ac.uk/take-part/citizen -science.html). Platforms like Zooniverse are also designing project builders which incorporate visual guides and step by step instructions for online volunteers. However, validation and cross-checking for data consistency need to be factored in by research teams (Borda, Gray and Fu 2019).

\section{CITIZEN SCIENCE ETHICS}

With a rise in public involvement in research, there are inevitable concerns being broached concerning citizen science approaches. An increasing number of studies are identifying possible ethical issues and offering guiding frameworks, such as how projects should be designed and acknowledgment of public contributions (Riesch and Potter 2014; Resnik 2015; Rasmussen and Cooper 2019). Rasmussen and Cooper (2019) also highlight that potential ethical issues not adequately represented in the literature are significant ethical questions about labour, equity, and compensation for citizen scientists.

The introduction of technologies such as machine learning, further contributes to ethical considerations of human labour, trust and bias, for example (Ceccaroni et al. 2019; Rasmussen and Cooper 
2019) and for which there are few concrete resolutions.

\section{CONCLUSION}

Overall, museums are important gatekeepers across science and society by providing frameworks for the active engagement of the public in discourse and enquiry (Simon 2010; Shirk et al. 2012; Ballard et al. 2017). This paper has provided some examples of the ways that citizen science, and particularly crowdsourcing, can advance scientific enquiry in the way that scientists alone cannot achieve.

Although our examples are mainly drawn from the USA and UK, due to their visibility online and in the literature, an international public is widely contributing to many of these projects, which are openly available on the Internet or supported by free apps, and some are leading more community-based initiatives using these tools and working principles. This form of distributed participation allows for significant opportunities to contribute to projects of shared concern or interest, to deepen connections, and generally to advance science learning and stewardship of the past, present, and future (Simon 2010). We believe that museums have a role in such efforts globally. We hope that this will add to the synergy of researchers and the public, helping to publicise and enable future collaborations.

\section{Acknowledgement}

Ann Borda received an Expert Visit grant in 2019 as part of the EU Horizon 2020 funded EPIC project. Jonathan Bowen is grateful to Museophile Limited for financial support.

\section{REFERENCES}

Ballard, H. L., Robinson, L. D., Young, A. N., et al. (2017) Contributions to conservation outcomes by natural history museum-led citizen science: Examining evidence and next steps. Biological Conservation, 208, pp. 87-97. DOI: 10.1016/i.biocon.2016.08.040

Beler, A., Borda, A., Bowen, J. P., and Filippini-Fantoni, S. (2004) The building of online communities: An approach for learning organizations, with a particular focus on the museum sector. In J. Hemsley, V. Cappellini, and G. Stanke (eds.), EVA 2004 London Conference Proceedings, University College London, UK, pp. 2.12.15. URL: https://arxiv.org/abs/cs/0409055

Boiano, S., Borda, A., and Gaia, G. (2019) Participatory innovation and prototyping in the cultural section: $A$ case study. In J. Weinel, J. P. Bowen, G. Diprose, and N. Lambert (eds.), EVA London 2019: Electronic Visualisation and the Arts, pp. 18-26. BCS, Electronic Workshops in Computing. DOI: 10.14236/ewic/ EVA2019.3

Bonacchi, C., Bevan, A., Keinan-Schoonbaert, A., Pett, D., and Wexler, J. (2019) Participation in heritage crowdsourcing. Museum Management and Curatorship, 34(2), pp. 166-182. DOI: 10.1080/09647775.2018.1559080

Bonney, R., Cooper, C. B., Dickinson, J. Kelling, S., et al. (2009) Citizen science: A developing tool for expanding science knowledge and scientific literacy. BioScience, 59(11), pp. 977-984. DOI: 10.1525/bio.2009.59.11.9

Borda, A. and Bowen, J. P. (2011) Virtual collaboration and community. In Information Resources Management Association (ed.), Virtual Communities: Concepts, Methodologies, Tools and Applications, chapter 8.9, pp. 2600-2611. IGI Global. DOI: 10.4018/978-1-60960-1003.ch809

Borda, A. and Bowen, J. P. (2019) Smart cities and digital culture: Models of innovation. In Giannini and Bowen (2019), chapter 27, pp. 523-549. DOI: 10.1007/978-3319-97457-6 28

Borda, A., Gray, K., and Downie, L. (2019) Citizen Science Models in Health Research: an Australian Commentary. Online Journal of Public Health Informatics, 11(3), e23, December. DOI: 10.5210/ojphi.v11i3.10358

Borda, A., Gray, K., and Fu, Y. (2019). Research Data Management in Health and Biomedical Citizen Science: Practices and Prospects. JAMIA Open, pp. 1-13, December. DOI: 10.1093/jamiaopen/ooz052

Bowen, J. P. (2008) Wiki software and facilities for museums. In D. Bearman and J. Trant (eds.), MW2008: Museums and the Web 2008, Montreal, Canada, Archives \& Museum Informatics. URL: http://www.archimuse.com/ mw2008/papers/bowen/bowen.html

Bowen, J. P. (2012) Alan Turing. In A. Robinson (ed.), The Scientists: An epic of discovery, pp. 270-275. Thames and Hudson.

Bowen, J. P. (2013) Online communities: Visualization and formalization. In Cyberpatterns 2013: Proc. Second International Workshop on Cyberpatterns - Unifying Design Patterns with Security, Attack and Forensic Patterns, Abingdon, UK, 8-9 July 2013. Oxford Brookes University, 2013. URL: https://arxiv.org/abs/1307.6145

Bowen, J. P. (2016) Alan Turing: Virtuosity and visualisation. In J. P. Bowen, G. Diprose, and N. Lambert (eds.), EVA London 2016: Electronic Visualisation and the Arts, pp. 197-204. BCS, Electronic Workshops in Computing. DOI: 10.14236/ewic/EVA2016.40

Bowen, J. P. (2017) Alan Turing: Founder of Computer Science. In J. P. Bowen, Z. Liu, and Z. Zhang (eds.), Engineering Trustworthy Software Systems: Second International School, SETSS 2016, Chongqing, China, March 28 - April 2, 2016. Springer, LNCS, vol. 10215, pp. 1-15. DOI: $10.1007 / 978-3-319-56841-61$

Bowen, J. P., Bennett, J., Borda, A., Hodges, A., FilippiniFantoni, S., and Beler, A. (2005) The development of science museum websites: Case studies. In L. T. W. Hin and R. Subramaniam (eds.), E-learning and Virtual Science Centers, Section 3: Case Studies, Chapter XVIII, pp. 366-392. Idea Group Publishing. DOI: 10.4018/978-159140-591-7.ch018

Bowen, J. P. and Borda, A. (2009) Communicating the public understanding of science: The Royal Society website. International Journal of Technology Management, 46(1/2), pp. 146-164. DOI: 10.1504/IJTM. $\underline{2009.022682}$ 
Ceccaroni, L., Bibby, J., Roger, E., Flemons, P., Michael, K., Fagan, L., and Oliver, J. L. (2019) Opportunities and risks for citizen science in the age of artificial intelligence. Citizen Science: Theory and Practice, 4(1), p.29. DOI: $\underline{10.5334 / \text { cstp.241 }}$

Copeland, B. J., Bowen, J. P., Sprevak, M., Wilson, R. J., et al. (2017) The Turing Guide. Oxford University Press. URL: https://en.wikipedia.org/wiki/The Turing Guide

Corbeil, S., Smith Hale, F., and Jaja, C. (2017) Crowdsourcing a nation. MW17: Museums and the Web. URL: https://mw17.mwconf.org/paper/crowdsourcing-anation/

Curtis, V. (2014) Online citizen science games: Opportunities for the biological sciences. Applied \& Translational Genomics, 3(4), pp. 90-94. DOI: 10.1016/j.atg.2014.07.001

ECSA (2015) Ten Principles of Citizen Science. European Citizen Science Association. URL: https://ecsa.citizenscience.net/sites/default/files/ecsa ten principles of citi zen science.pdf

Gaia, G., Boiano, S. and Borda, A. (2019) Engaging museum visitors with Al: The case of chatbots. In Giannini and Bowen (2019), chapter 15, pp. 309-329. DOI: 10.1007/978-3-319-97457-6 15

Gaia, G., Boiano, S. Bowen, J. P., and Borda, A. (2020) Museum websites of the first wave: The rise of the virtual museum. In J. Weinel, J. P. Bowen, G. Diprose, and N. Lambert (eds.), EVA London 2020: Electronic Visualisation and the Arts, this volume. BCS, Electronic Workshops in Computing.

Giannini, T. and Bowen J. P. (eds.) (2019) Museums and Digital Culture: New perspectives and research. Springer, Series on Cultural Computing. DOI: 10.1007/978-3-319$\underline{97457-6}$

Haklay, M. (2018) Participatory citizen science. In Hecker, S., Haklay, M., Bowser, A., Makuch, Z., Vogel, J. \& Bonn, A. (eds.), Citizen Science: Innovation in Open Science, Society and Policy, pp. 52-62. London: UCL Press.

Hedges, M. and Dunn, S. (2017). Academic Crowdsourcing in the Humanities: Crowds, communities, and co-production. Cambridge, MA: Elsevier Science.

Hodges, A. (1983/2012) Alan Turing: The Enigma, Simon and Schuster / Princeton University Press.

Irwin, A. (1995) Citizen Science: A study of people, expertise and sustainable development. London: Routledge.

Kelling, S., Fink, D., La Sorte, F. A., et al. (2015) Taking a 'Big Data' approach to data quality in a citizen science project. Ambio, 44(S4), pp. 601-611. DOI: 10.1007/s13280-015-0710-4

Leach, B., et al. (2020) Emerging developments in citizen science: Reflecting on areas of innovation. Santa Monica, CA: RAND Corporation. URL: https://www.rand.org/ pubs/research reports/RR4401.html

Liu, A. H.-Y. and Bowen, J. P. (2011) Creating online collaborative environments for museums: A case study of a museum wiki. International Journal of Web Based Communities, 7(4), pp. 407-428. DOI: 10.1504/IJWBC. $\underline{2011.042988}$
Mollica, J. (2017) Send Me SFMOMA. San Francisco Museum of Modern Art, USA, July 2017. URL: https://www.sfmoma.org/read/send-me-sfmoma/

Owens, T. (2013) Digital Cultural Heritage and the Crowd. Curator: The Museum Journal, 56(1), pp. 121-130. DOI: 10.1111/cura.12012

Rasmussen, L.M. and Cooper, C. (2019) Citizen science ethics. Citizen Science: Theory and Practice, 4(1), p. 5. DOI: $10.5334 /$ cstp.235

Resnik; D. B., Elliot; K. C., and Miller, A. K. (2015) A framework for addressing ethical issues in citizen science. Environmental Science \& Policy, 54, pp. 475-481. DOI: 10.1016/..envsci.2015.05.008

Ridge, M. (2014) Crowdsourcing our cultural heritage: Introduction. In M. Ridge (ed.), Crowdsourcing our Cultural Heritage, pp. 1-14. London: Ashgate.

Riesch, H. and Potter, C. (2014) Citizen science as seen by scientists: Methodological, epistemological and ethical dimensions. Public Understanding of Science, 23(1): 107120. DOI: $10.1177 / 0963662513497324$

Sforzi, A. et al. (2018) Citizen science and the role of natural history museums. In S. Hecker, M. Haklay, A. Bowser, Z. Makuch, J. Vogel, and A. Bonn (eds.) Citizen Science: Innovation in Open Science, Society and Policy, pp. 429-444. London: UCL Press.

Shirk, J. L., Ballard, H. L., Wilderman, C. C., et al. (2012) Public participation in scientific research: A framework for deliberate design. Ecology and Society, 17(2), p. 29. DOI: 10.5751/ES-04705-170229

Simon, N. (2010) The Participatory Museum. Museum 2.0. URL: http://www.participatorymuseum.org

Swinton, J., Ochu, E., and The MSI Turing's Sunflower Consortium (2016) Novel Fibonacci and non-Fibonacci structure in the sunflower: Results of a citizen science experiment. Royal Society Open Science. DOI: 10.1098/rsos.160091

Turing, A. M. (1952) The chemical basis of morphogenesis. Philosophical Transactions of the Royal Society of London, 237(641), pp. 37-72. DOI: 10.1098/rstb.1952.0012

Vincent, M. L., Gutierrez, M. F., Coughenour, C., et al. (2015) Crowd-sourcing the 3D digital reconstructions of lost cultural heritage. In 2015 Digital Heritage, 1, pp. 171172. IEEE. DOI: 10.1109/DigitalHeritage.2015.7413863

Wang, M. and Nunes, M. (2019) Matching serious games with museum's educational roles: smart education in practice. Interactive Technology and Smart Education, 16(4), pp. 319-342. DOI: 10.1108/ITSE-03-2019-0013

Wikipedia (2020) Citizen science. Wikipedia. URL: https://en.wikipedia.org/wiki/Citizen science

Winchester, S. (2003) The Meaning of Everything. Oxford University Press.

Wyman, B., et al. (2006) Steve.museum: An Ongoing Experiment in Social Tagging, Folksonomy, and Museums, in J. Trant and D. Bearman (eds.), Museums and the Web 2006: Proceedings, Toronto: Archives \& Museum Informatics. URL: http://www.archimuse.com/mw2006/papers/wyman/wyman.html 